DOI: http://dx.doi.org/10.20535/2219-380414201678423

S. I. Trubachev ${ }^{1}$, candidate of technical sciences, O. N. Alekseychuk ${ }^{2}$, candidate of technical sciences

\title{
VIBRATIONS OF LAMELLAR AND ROD STRUCTURES WITH ENERGY DISSIPATION
}

Ua Розглядаються коливання нелінійно пружніх стержнів та пластин 3 урахуванням гістерезисного тертя. Нелінійна задача розвязується за допомогою метода розкладу за малим параметром. Для визначення власних частот та форм коливань використовується варіаційно-сітковий підхід побудови функціоналів типу Релея та мінімізація їх методом по-координатного спуску. Задача про вимушені коливання розв'язується шляхом розкладу за власними формами.

Ru Рассматриваются колебания нелинейно упругих стержней и пластин с учетом гистерезисного трения. Нелинейная задача решается с помощью метода разложения по малому параметру. Для определения собственных частот и форм колебаний используется вариационно-сеточный подход построения функционалов типа Рэлея и минимизация их методом покоординатного спуска. Задача о вынужденных колебаниях решается путем разложения по собственным формам.

\footnotetext{
${ }^{1}$ National Technical University of Ukraine "Kyiv Polytechnic Institute"

${ }^{2}$ National Technical University of Ukraine "Kyiv Polytechnic Institute", department of theoretical mechanics
} 


\section{Introduction}

It is known that plate and rod designs are widely used in the aircraft industry because the research of oscillations with considering the energy dissipation is very topical task. It should be stressed, to solve the problem of vibration of the mechanical system, we first need to determine the spectrum of frequencies and forms of oscillations. In this paper we are confine ourselves to the bending vibrations of thin plates and rods. In the derivation of differential equations we will use the simple assumption [1], the dependences between deformation and movement are linear, and there are linear physical equations instead of Hooke's law.

\section{Formulation and solving the problem}

Been using the method and the designation [1], we'll get from the conditions of dynamic equilibrium of the plate elements

$$
\frac{\partial^{2} M_{y}}{\partial x^{2}}+2 \cdot \frac{\partial^{2} M_{x y}}{\partial x \partial y} \cdot \frac{\partial^{2} M_{x}}{\partial x y^{2}}+\rho-\frac{\gamma}{g} \cdot h \cdot \frac{\partial^{2} \omega}{\partial x t^{2}}=0 .
$$

The moments that were introduced in equation (1) should be expressed through the plate deflection $\omega(x, y)$. We'll use the formula of recorded stresses in the plate theory for the nonlinear case for this purpose, [1]

$$
\begin{gathered}
\sigma_{11}=3 K\left[1-\varepsilon \sum\left(b_{n}+\beta_{n} I^{n+1}\right) e^{n}\right]+2 G\left[1-\varepsilon \sum\left(d_{n}+\delta_{n} I^{n+1}\right) \gamma_{u}{ }^{n}\right]\left(\varepsilon_{11}-e\right), \\
\sigma_{22}=3 K\left[1-\varepsilon \sum\left(b_{n}+\beta_{n} I^{n+1}\right) e^{n}\right]+2 G\left[1-\varepsilon \sum\left(d_{n}+\delta_{n} I^{n+1}\right) \gamma_{u}{ }^{n}\right]\left(\varepsilon_{22}-e\right), \\
\sigma_{12}=G\left[1-\varepsilon \sum\left(d_{n}+\delta_{n} I^{n+1}\right) \gamma_{u}{ }^{n}\right] \varepsilon_{12},
\end{gathered}
$$

where $\varepsilon-$ is a small parameter,

whereas $\sigma_{33} \approx 0$, then $\sigma=\frac{\sigma_{11}+\sigma_{22}}{2}$ and

$$
e=\frac{\sigma_{11}+\sigma_{22}}{9 K\left[1-\varepsilon \sum_{n}\left(b_{n}+\beta_{n} I^{n+1}\right) e^{n}\right]} .
$$

Substituting the (5) in (2) and (3), after transformations we obtain 


$$
\begin{aligned}
& \sigma_{11}=\frac{2 G}{1-\mu}\left[1-\varepsilon \sum_{n}\left(d_{n}+\delta_{n} I^{n+1}\right) \gamma_{u}{ }^{n}\right]\left(\varepsilon_{11}-\tilde{\mu} \varepsilon_{22}\right), \\
& \sigma_{22}=\frac{2 G}{1-\mu}\left[1-\varepsilon \sum_{n}\left(d_{n}+\delta_{n} I^{n+1}\right) \gamma_{u}{ }^{n}\right]\left(\varepsilon_{22}-\tilde{\mu} \varepsilon_{11}\right) .
\end{aligned}
$$

Where

$$
\tilde{\mu}=\frac{1}{2} \frac{3 K\left[1-\varepsilon \sum_{n}\left(b_{n}+\beta_{n} I^{n+1}\right) e^{n}\right]-2 G\left[1-\varepsilon \sum_{n}\left(d_{n}+\delta_{n} I^{n+1}\right) \gamma_{u}{ }^{n}\right]}{3 K\left[1-\varepsilon \sum_{n}\left(b_{n}+\beta_{n} I^{n+1}\right) e^{n}\right]+G\left[1-\varepsilon \sum_{n}\left(d_{n}+\delta_{n} I^{n+1}\right) \gamma_{u}{ }^{n}\right]}
$$

If $\varepsilon=0$, i. e. $b_{n}-\beta_{n}=d_{n}=\delta_{n}=0$, then (7) will transformed into a known expression Poisson's ratio $\mu$ through the modules of elasticity $G$ i $K$ :

$$
\mu=\frac{1}{2} \frac{3 K-2 G}{3 K+G} .
$$

\section{Method of calculation}

For the calculation the approximate asymptotic methods of the theory of nonlinear oscillations were used [2]. Schedule (7) in a Taylor series in the vicinity $\varepsilon=0$ of quantities degrees $\varepsilon\left(b_{n}+\beta_{n} I^{n+1}\right), \varepsilon\left(d_{n}+\delta_{n} I^{n+1}\right)$

$$
\tilde{\mu}=\mu-\varepsilon \frac{(1+\mu)(1-2 \mu)}{3} \sum_{n}\left[\left(b_{n}+\beta_{n} I^{n+1}\right) e^{n}-\left(d_{n}+\delta_{n} I^{n+1}\right) \gamma_{u}{ }^{n}\right]-\varepsilon^{2} \ldots
$$

Thus, Poisson's ratio in real bodies is not constant, but varies in depending on the magnitude of deformation $\left(e, \gamma_{u}\right)$.

By using the analytical decomposition we will get

$$
\frac{\mu}{1-\tilde{\mu}}=\frac{1}{1-\mu}\left\{\mu-\varepsilon(1+\mu) Q \sum_{n}\left[\left(b_{n}+\beta_{n} I^{n+1}\right) e^{n}-\left(d_{n}+\delta_{n} I^{n+1}\right) \gamma_{u}{ }^{n}\right]-\varepsilon^{2} \ldots\right\}
$$
cy (4))

By substituting (9) and (10) to (6), we get up to a $\varepsilon^{2}$ (of equal accura- 


$$
\begin{aligned}
\sigma_{11} & =\frac{2 G}{1-\mu}\left(\varepsilon_{11}+\mu \varepsilon_{22}\right)-\varepsilon \frac{2 G}{1-\mu} \sum_{n}\left[(1+\mu) Q\left(b_{n}+\beta_{n} I^{n+1}\right) e^{n}\left(\varepsilon_{11}+\varepsilon_{22}\right)-\right. \\
& \left.-\left(d_{n}+\delta_{n} I^{n+1}\right) \gamma_{u}{ }^{n}\left(\mu_{4} \varepsilon_{11}+\mu_{5} \varepsilon_{22}\right)\right] \\
\sigma_{22} & =\frac{2 G}{1-\mu}\left(\varepsilon_{22}+\mu \varepsilon_{11}\right)-\varepsilon \frac{2 G}{1-\mu} \sum_{n}(1+\mu) Q\left(b_{n}+\beta_{n} I^{n+1}\right) e^{n}\left(\varepsilon_{11}+\varepsilon_{22}\right)- \\
& \left.-\left(d_{n}+\delta_{n} I^{n+1}\right) \gamma_{u}{ }^{n}\left(\mu_{4} \varepsilon_{22}+\mu_{5} \varepsilon_{11}\right)\right]
\end{aligned}
$$

where the constants $\mu_{4}=Q(1+\mu)-1, \quad \mu_{5}=Q(1+\mu)-\mu, \quad Q=\frac{1-2 \mu}{3(1-\mu)}$.

From the theory of plates is known that

$$
\varepsilon_{11}=-\frac{\partial^{2} \omega}{\partial x^{2}} z, \quad \varepsilon_{22}=-\frac{\partial^{2} \omega}{\partial y^{2}} z, \quad \varepsilon_{12}=-\frac{\partial^{2} \omega}{\partial x \partial y} z, \quad \varepsilon_{23}=\varepsilon_{31}=0 .
$$

The relatively small transverse deformation $\varepsilon_{33}$, that enters through the $e, \gamma_{u}$ only into members of equations (4) and (11) that are proportional to a small parameter $\varepsilon$, should be taken up to $\varepsilon$, i.e. can be taken, as in the linear theory,

$$
\varepsilon_{33}=-\frac{\mu}{1-\mu}\left(\varepsilon_{11}+\varepsilon_{22}\right)=-\frac{\mu}{1-\mu}\left(\frac{\partial^{2} \omega}{\partial x^{2}}+\frac{\partial^{2} \omega}{\partial x^{2}}\right) z .
$$

Then

$$
\begin{gathered}
e=Q\left(\varepsilon_{11}+\varepsilon_{22}\right) \\
\gamma_{u}=\frac{2}{\sqrt{3}} \sqrt{\frac{2}{3}\left[\mu_{1}\left(\varepsilon_{11}^{2}+\varepsilon_{22}^{2}\right)+\mu_{2} \varepsilon_{11} \varepsilon_{22}+\frac{1}{2} \varepsilon_{12}^{2}\right]}
\end{gathered}
$$

or with considering (12) i (13)

$$
\begin{gathered}
e=-Q\left(\frac{\partial^{2} \omega}{\partial x^{2}}+\frac{\partial^{2} \omega}{\partial x^{2}}\right) z \\
\gamma_{u}=\sqrt{\frac{8}{9} \mu_{1}\left[\left(\frac{\partial^{2} \omega}{\partial x^{2}}\right)^{2}+\left(\frac{\partial^{2} \omega}{\partial y^{2}}\right)^{2}\right]+\mu_{2} \frac{\partial^{2} \omega}{\partial x^{2}} \cdot \frac{\partial^{2} \omega}{\partial y^{2}}+3\left(\frac{\partial^{2} \omega}{\partial x \partial y}\right)^{2}} z .
\end{gathered}
$$

Where the constants $\mu_{1}$ and $\mu_{2}$ are determined by Poisson coefficient $\mu$, which is appropriate to linear case (the endangered small deformation): 


$$
\mu_{1}=\frac{\mu}{\left(1-\mu^{2}\right)^{2}}+1, \quad \mu_{2}=\frac{\mu}{\left(1-\mu^{2}\right)^{2}}-1 .
$$

By replacing in the formulas (4) and (11) moving through the strain in according to dependencies (12), (16) and (17) and setting the necessary moments by using the obtained ratios.

$$
M_{y}=\int_{-\frac{h}{2}}^{\frac{h}{2}} \sigma_{11} z d z, \quad M_{z}=\int_{-\frac{h}{2}}^{\frac{h}{2}} \sigma_{22} z d z, \quad M_{x y}=\int_{-\frac{h}{2}}^{\frac{h}{2}} \sigma_{12} z d z
$$

We obtain

$$
\begin{aligned}
& M_{x}=-D\left(\frac{\partial^{2} \omega}{\partial x^{2}}+\mu \frac{\partial^{2} \omega}{\partial y^{2}}\right)+\varepsilon D\left[L(x, y)+N_{1}(x, y)\right], \\
& M_{y}=-D\left(\frac{\partial^{2} \omega}{\partial y^{2}}+\mu \frac{\partial^{2} \omega}{\partial x^{2}}\right)+\varepsilon D\left[L(x, y)+N_{2}(x, y)\right], \\
& M_{x y}=-D(1-\mu) \frac{\partial^{2} \omega}{\partial x \partial y}+\varepsilon D(1-\mu) \cdot N_{3}(x, y) .
\end{aligned}
$$

Here is

$$
\begin{aligned}
& L(x, y)=(1+\mu) \sum_{n}\left(b_{n}+\beta_{n} I^{n+1}\right) \cdot \frac{J^{n}}{J} \cdot Q^{n+1} \cdot\left(\frac{\partial^{2} \omega}{\partial x^{2}}+\mu \frac{\partial^{2} \omega}{\partial x^{2}}\right)^{2} \\
& N_{1}(x, y)=N(x, y) \cdot\left(\mu_{4} \frac{\partial^{2} \omega}{\partial x^{2}}+\mu_{5} \frac{\partial^{2} \omega}{\partial y^{2}}\right) ; \\
& N_{2}(x, y)=N(x, y) \cdot\left(\mu_{4} \frac{\partial^{2} \omega}{\partial y^{2}}+\mu_{5} \frac{\partial^{2} \omega}{\partial x^{2}}\right) ; \\
& N_{3}(x, y)=N(x, y) \frac{\partial^{2} \omega}{\partial x \partial y} ; \\
& N(x, y)=\sum_{n}\left(d_{n}+\delta_{n} I^{n+1}\right) \cdot \frac{J^{n}}{J} \cdot\left(\frac{8}{9}\right)^{\frac{n}{2}} \cdot\left(\mu_{1}\left(\frac{\partial^{2} \omega}{\partial x^{2}}\right)^{2}+\mu_{1}\left(\frac{\partial^{2} \omega}{\partial y^{2}}\right)^{2}+\right. \\
& \left.+\mu_{2} \cdot \frac{\partial^{2} \omega}{\partial y^{2}} \cdot \frac{\partial^{2} \omega}{\partial x^{2}}+3\left(\frac{\partial^{2} \omega}{\partial x \partial y}\right)^{2}\right) ;
\end{aligned}
$$




$$
D=\frac{E h^{3}}{12\left(1-\mu^{2}\right)}=\frac{E J}{1-\mu^{2}}=2 \cdot \frac{G I}{1-\mu} ; \quad \frac{J_{n}}{J}=\frac{3}{n+3}\left(\frac{h}{2}\right)^{n} \text {. }
$$

$h-$ is the plate thickness;

$n-$ is an even integer.

For odd $n, J_{n}=\iint_{(F)} z^{n+2} d F=0$, if only nonlinear terms in (4) and (11) with odd indices are not adopted to describe the a skew-symmetric deformation diagrams and, as a result, $\left|e^{n}\right|,\left|\gamma_{и}^{n}\right|$ are not taken in magnitude. In the latter case $J_{n} \neq 0$ for odd $n$.

After substitution (18) into (1), we obtain the equation of physically nonlinear oscillations of the constant thickness plate, which is by using the harmonic operator

$$
\Delta=\frac{\partial^{2}}{\partial x^{2}}+\frac{\partial^{2}}{\partial y^{2}}
$$

is written as:

$$
\Delta \Delta \omega+\frac{y h}{g D} \cdot \frac{\partial^{2} \omega}{\partial t^{2}}=\frac{P}{D}+\varepsilon\left[\frac{\partial^{2} N_{1}}{\partial x^{2}}+\frac{\partial^{2} N_{2}}{\partial y^{2}}+\Delta L+2(1-\mu) \frac{\partial^{2} N_{3}}{\partial x \partial y}\right]
$$

Equation of physically nonlinear flexural vibrations of the rod can be obtained if instead of a linear ratio

$$
M=E J \frac{\partial^{2} \omega}{\partial x^{2}}
$$

the equality which is coming out from the linear relationship between stress and deformation [2] will be accepted

$$
M=E J \cdot \frac{\partial^{2} \omega}{\partial x^{2}}-\varepsilon E \cdot \sum_{n}\left(a_{n}+a_{n} I^{n+1}\right) \cdot J_{n} \cdot\left(\frac{\partial^{2} \omega}{\partial x^{2}}\right)^{n+1}
$$

Where $\omega(x)$ is the deflection of the rod: $J=\iint_{(F)} z^{2} d F$, $J_{n}=\iint_{(F)} z^{n+2} d F, \quad \varepsilon-$ is a small parameter.

We'll come to the equation of the rod bending vibrations with nonlinearity by substituting the obtained expression (20) to the equation of oscillations of the $\operatorname{rod}[1]$.

$$
\frac{\partial^{2}}{\partial x^{2}}\left[E J \frac{\partial^{2} \omega}{\partial x^{2}}\right]+\frac{y}{g} F \frac{\partial^{2} \omega}{\partial t^{2}}=\rho+\varepsilon \sum_{n} \frac{\partial^{2}}{\partial x^{2}}\left[E J_{n}\left(a_{n}+a_{n} I^{n+1}\right)\left(\frac{\partial^{2} \omega}{\partial x^{2}}\right)^{n+1}\right] .
$$

A distributed external load $p$ is small as compared to the forces of elasticity and inertia forces in forced resonant vibrations. Therefore, before it is possible to put a small parameter $\varepsilon$ in equations (21) and (19). Then for solving these nonlinear equations asymptotic methods N. M. Krylov - N. N. Bogolyubov can 
be applied [2]. If the distributed load $\mathrm{p}$ is not small, that it is possible, for example, in the non-resonant forced oscillations, that, by the relevant change of variables [2] the equation is need to be converted to the form when the asymptotic methods are applied.

It should be emphasized that the problem of forced vibrations cannot be solved if the spectrum of natural frequencies and forms of vibrations is not determined. For the determination of natural frequencies and forms of the plate and rod structures vibrations is proposed to use an approach which is based on the variational - grid method of forming the finite-dimensional Rayleigh's type functional, and its minimization by a method coordinate-wise descent, which is one of the methods of nonlinear programming [3]. For building of the necessary functionals are invited to apply the increase stiffnesses method [3]. Then, the determination of natural frequencies and forms of the mechanical system vibrations comes down to minimization problem:

$$
\omega_{\kappa}^{2}=\inf _{u \in R^{N}} \frac{(\tilde{K} u, u)+c \sum_{k=1}^{l-1}\left(M z_{k}, u\right)}{(M u, u)} .
$$

Where $(K u, u)$ and $(M u, u)$ are the quadratic forms, that are corresponding to the potential and kinetic energy of the system; $K$ and $M$ are the stiffness and mass matrices, respectively, $u$ is the vector of displacement, $z$ is the desired form of vibrations. From the Rayleigh ratio type (2.4.15) follows that in the calculation process there is no need to build projectors that are corresponding to found eigenvector, but enough to keep in computer memory only its own vector, and greatly simplifies its denominator. This allows to find the spectrum of frequencies and forms with less computational costs in comparison with the traditional approach. After the determination of natural frequencies and forms of vibrations the problem of forced vibrations of structures can be found by expanding their own forms of vibrations.

\section{Conclusions}

In this work the nonlinear vibrations of elastic rods and plates with taking into account the hysteresis friction were examined. The problem was solved by a method of decomposition on the small parameter. For the determination of mechanical systems natural frequencies and forms of vibrations was used the variation- grid method of forming the Rayleigh's type functionals and their minimization by coordinate-wise descent method. This approach will allow to solve the problem of nonlinear oscillations of elastic plates and rods, as the elements that are used in the aircraft industry. 


\section{References}

1. Василенко, М. В. Теорія коливань та стійкості руху. / М. В. Василенко, О. М. Алексейчук// -К.: Вища шк., 2004.-525 с.

2. Боголюбов, Н. Н. Асимптотические методы в теории нелинейных колебаний / Н. Н. Боголюбов, Ю. А. Митропольский // М.: Наука, 1974.$504 \mathrm{c}$.

3. Бабенко, А. $Є$. Применение и развитие метода покоординатного спуска в задачах определения напряженно-деформированного состояния при статических и вибрационных загрузках / А. Є. Бабенко, Н. И. Бобырь, С. Л. Бойко, О. А. Боронко//К.: Инрес, 2005.-264 с. 